\title{
Design and Implementation of Campus Real-Time Monitoring and Emergency Management System Based on GIS
}

\author{
Shengwu Duan \\ School of Geographical Sciences \\ Northeast Normal University, 130024 \\ Changchun, China \\ duansw444@nenu.edu.cn
}

\author{
Sijun Jia \\ School of Geographical Sciences \\ Northeast Normal University, 130024 \\ Changchun, China \\ jiasj158@nenu.edu.cn
}

\begin{abstract}
With the increasing number of undergraduates, the security problem of campus has been greatly drawn attention from the education world. This paper is based on the theories of campus security management combined with practical situation. It summary the database design, function design and spatial data model of real time monitoring emergency management system which provides a new train of thought for campus security manage by informatization and digitization.
\end{abstract}

Keywords-campus security management; GIS secondary development; digital campus

\section{INTRODUCTION}

Since the implementation of the strategy of rejuvenating China through science and education, our country's higher education has appeared to develop rapidly. In recent years, the overall numbers of college students continue to grow. According to the statistics showed in the National Education Development Bulletin, in 1990, the number of the undergraduates and junior college students reached 608,900. The enrollment rate of higher education was about $25 \%$ in 2010 , and the number of students was from 2,800 to 3,000 . Ma Jiajue event, Fudan poisoning case and so many vicious injuries in campus had a strong psychological impact on the students and staff. These events are warning us, campus crisis has not only limited to qualitative accidents and natural disasters in traditional sense[1].

Due to the increasingly demands for education, the existing education resources appeared to be significantly inadequate[1]. Many colleges began to build new campus to cope with the situation. However, as the construction and progress of infrastructure, the disaster prevention emergency work is failed to develop in a synchronous way. Some obvious and severe security problems of campus have raised greatly concern from the educational world. Therefore, building up a security safeguard platform while is suitable for the campus practical situation is the extensive market requirement for the campus security and emergency management and is also an urgent demand for campus informatization development.

\section{THE INTRODUCTION OF GIS}

A geographic information system (GIS) is a system designed to capture, store, manipulate, analyze, manage, and present all types of geographical data. The acronym GIS is sometimes used for geographical information science or geospatial information studies to refer to the academic discipline or career of working with geographic information systems and is a large domain within the broader academic discipline of Geo-informatics. A GIS can be thought of as a system that provides spatial data entry, management, retrieval, analysis, and visualization functions. The implementation of a GIS is often driven by jurisdictional (such as a city), purpose, or application requirements. Generally, a GIS implementation may be custom-designed for an organization. Hence, a GIS deployment developed for an application, jurisdiction, enterprise, or purpose may not be necessarily interoperable or compatible with a GIS that has been developed for some other application, jurisdiction, enterprise, or purpose. What goes beyond a GIS is a spatial data infrastructure, a concept that has no such restrictive boundaries.

By the end of the 20th century, the rapid growth in various systems had been consolidated and standardized on relatively few platforms and users were beginning to explore viewing GIS data over the Internet, requiring data format and transfer standards. More recently, a growing number of free, open-source GIS packages run on a range of operating systems and can be customized to perform specific tasks. Increasingly geospatial data and mapping applications are being made available via the Internet.

Many colleges and universities realized that security management can't depart from the support of information technology, so they developed much software to assistant security management[2]. However, there are lots of aspects to be considered. The traditional management just relies on text data, forms which obviously can't meet the demand of the visualization and dynamics of security emergency. Moreover, most of the management object also contains a lot of spatial geographic information which traditional relational database display less intuitively. GIS has good spatial geographic data visualization function and strong analysis ability which can fix the problems above. 


\section{SYSTEM DESIGN}

\section{A. Database Structural Design}

Figure 1 shows the database structure model. According to the system analysis, this system consists of spatial database and attribute database.

\section{B. Functional Design}

In the design of campus real time monitoring emergency management system, we put informatization and standardization of campus security management in the first place, and integrate the supervising system to implement its complex function framework as shown in Figure 2[3].

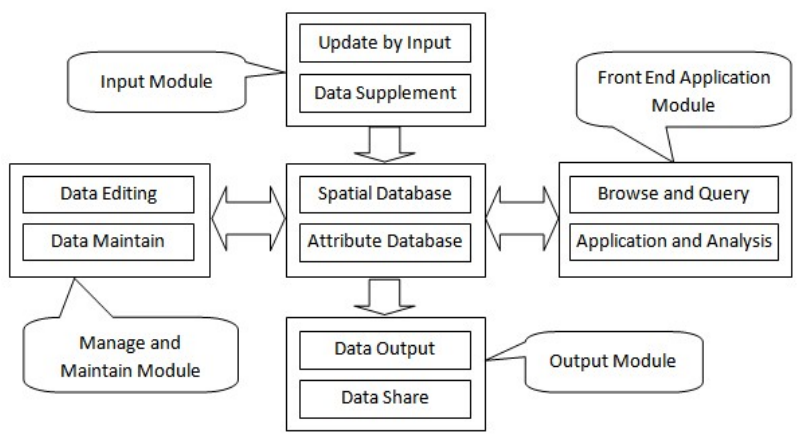

Figure 1. The structure of the system design model

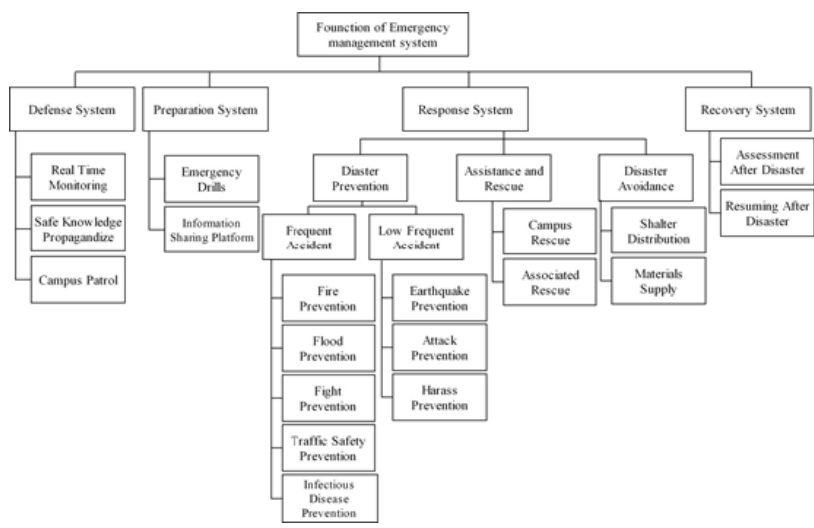

Figure 2. The function frame

- The main function of defense system is the disaster education and publicity. Predicte possible emergencies and develop preventive measures. Make decision and response measures to the changing situations.

- The main component of prevention system are emergency drills and information sharing platform.

- Response system is divided into three parts: disaster prevention, assistance and rescue and disaster avoidance. This system is the core part of the whole software.
- The main function of recovery system is to assess and resume after disaster. For example: compensate for disaster loss.

\section{SySTEM IMPLEMENTATION}

\section{A. Software Development Environment}

SuperMap Objects (COM) is a full-component platform for developing professional GIS applications. It is based on Microsoft's COM technology, and has a collection of COM objects that developers can use to create custom applications.

SuperMap Objects (COM) is comprised of a large number of ActiveX controls and Automation Objects. Developers can embed them in Visual Basic, Visual C++, Visual Basic .NET, Visual C\# .NET, and many other programming tools to develop GIS applications according to different needs[4].

This system developed by Visual Studio 2010(c\#.NET Framework 3.5), SuperMap Objects 6.0 and SQL Server 2005 and also beautified by Developer Express 2010 vol 1 widget.

\section{B. Database Construction}

The data used in this paper are stored in both spatial and attribute database.

- The main steps of spatial database establishment are a) data preprocessing: campus cadastral data is used in this system and the projection is UTM; b) data entry: mouse tracking method; c) data editing: edit data in Supermap Desktop to improve editing efficiency; d) establishment of the topology: check the topology of data to make sure on topology error. Figure 3 and Figure 4 show the raster and vector maps of spatial database[5].

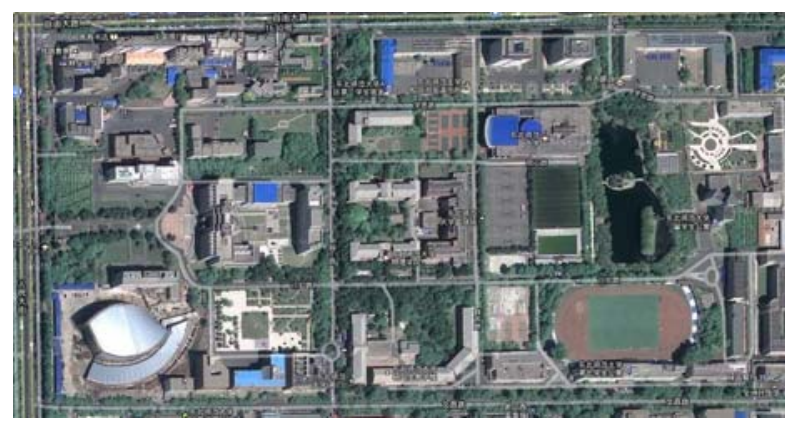

Figure 3. Raster map 


\section{CONCLUSION}

Currently, the campus-level security emergency system has been applied precedent, but not widespread[6]. In order to introduce research results into the existing campus fire emergency system, on the one hand needs to pay attention to the risk and hazardous of accidents on campus, on the other hand we must also make full use of the existing campus network and campus management information system to establish the emergency systems based on WebGIS and GIS secondary development technologies. Only in this way can we achieve the sharing of resources, overall planning, rational distribution, reduce duplication of work. In addition, we should pay attention to the combination of GIS and campus safety assessment module, evacuation module, decision support module so as to lay a good foundation for improving campus emergency management in the future.

The digital campus is the inevitable trend of development of modern distance education and network. The combination of traditional information management system and GIS shows that GIS technology has strong vitality. In this paper, we developed campus emergency system and explored the key technologies and methods in combining GIS with security management. When compared with the traditional management system, it has geography meaning like spatial analysis. It reflects the prospect of technological of geographical information science. Therefore, this system provides a new way for campus security research and accumulates valuable experience.

\section{REFERENCES}

[1] BAI Tao, Xu Zhonghu,"Countermeasures of crisis management in Colleges,” Journal of South China University of Technology (Social Science Endition), vol. 7, 2005, pp. 67-71.

[2] LIANG Ming, ZHU Jie.”Study On the Application of GIS in College Safety Management," Journal of Anhui Institute of Architecture \& Industry, vol. 16, 2008, pp. 97-100.

[3] SONG Jianhu, LU Yingjun, ZHU Qiuli," Approach to the Applications and Development of GIS,” Geomathics \& Spatial Information Techology, vol. 27, 2004, pp. 18-20.

[4] The editorial board, "SuperMap Objects Component based software development,” Tsinghua University press, 2008, Beijing

[5] NIE Yan, NIE Yimin, "Research and Discussion of 3D Virtual Campus Based on ArcGIS," Journal of Shandong Agricultural University(Natural Science), vol. 40, 2009, pp. 283-286.

[6] FENG Xiaogang, WANG Xiangdong, TANG Dongmei, Geospatial Iinformation "Design and Realization of the Digital Campus Based on the MapInfo", vol. 6, 2008, pp.62-64.. 